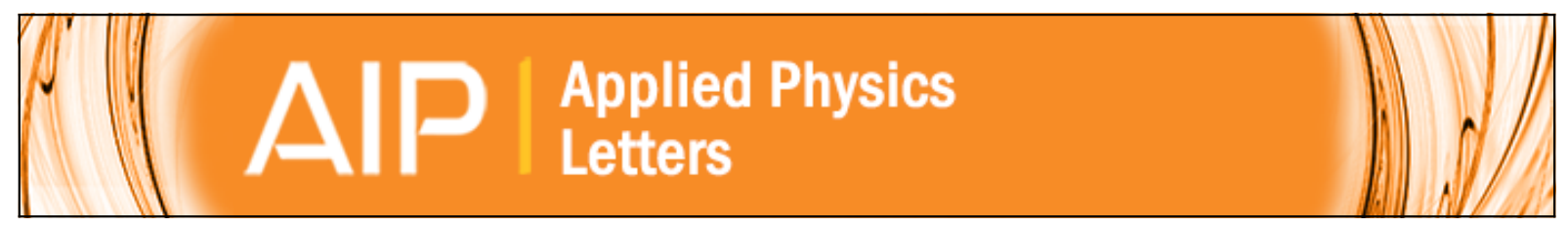

\title{
Electrical activation of carbon in GaAs: Implantation temperature effects
}

I. Danilov, J. P. de Souza, A. V. Murel, and M. A. A. Pudenzi

Citation: Applied Physics Letters 78, 1700 (2001); doi: 10.1063/1.1356729

View online: http://dx.doi.org/10.1063/1.1356729

View Table of Contents: http://scitation.aip.org/content/aip/journal/apl/78/12?ver=pdfcov

Published by the AIP Publishing

\section{Articles you may be interested in}

Carbon reactivation kinetics in GaAs: Its dependence on dopant precursor, doping level, and layer thickness J. Appl. Phys. 91, 5923 (2002); 10.1063/1.1467953

Increased electrical activation in the near-surface region of sulfur and nitrogen coimplanted $\mathrm{GaAs}$ Appl. Phys. Lett. 77, 3607 (2000); 10.1063/1.1328766

Carrier distribution profiles in Si-doped layers in GaAs formed by focused ion beam implantation and successive overlayer growth

J. Vac. Sci. Technol. B 18, 3158 (2000); 10.1116/1.1319683

Photoluminescence study of implantation dose and dose-rate dependence of Si doping of GaAs

Appl. Phys. Lett. 70, 3597 (1997); 10.1063/1.119244

Activation modeling of Si implanted GaAs

J. Appl. Phys. 81, 1131 (1997); 10.1063/1.363858

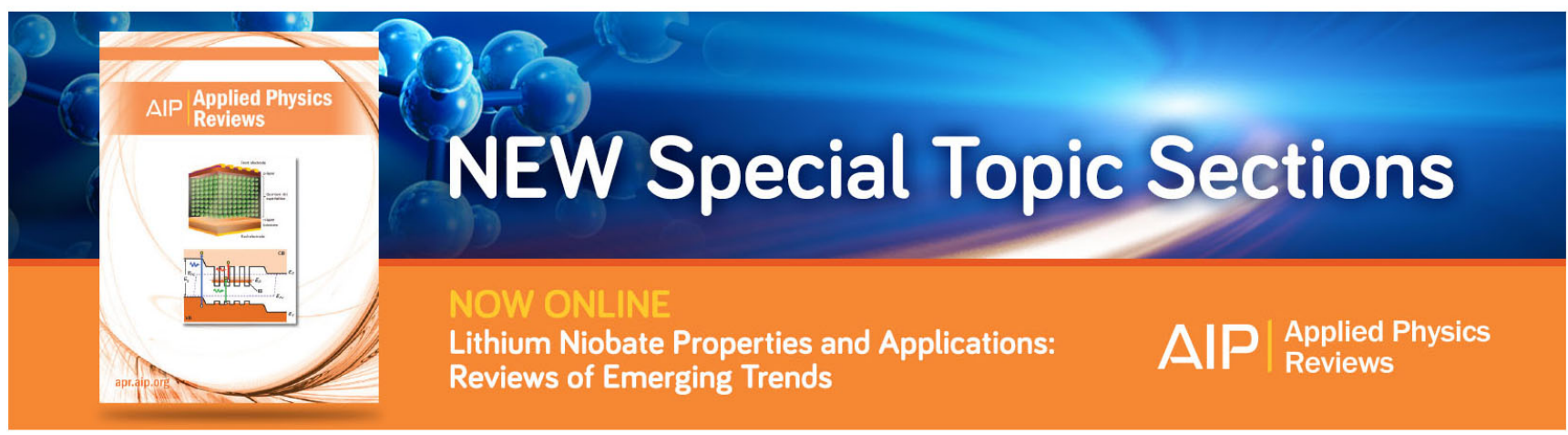




\section{Electrical activation of carbon in GaAs: Implantation temperature effects}

I. Danilov and J. P. de Souza

Instituto de Fisica, Universidade Federal do Rio Grande do Sul, 91501-970, Porto Alegre, R.S., Brazil

A. V. Murel

Institute of Physics for Microstructures, RAN, 603600, Nizhny Novgorod, Russia

M. A. A. Pudenzia)

Instituto de Fisica "Gleb Wataghin," Universidade Estadual de Campinas, 13081-970 Campinas, S.P., Brazil

(Received 13 October 2000; accepted for publication 26 January 2001)

Carbon was implanted into GaAs at the energy of $1 \mathrm{MeV}$ with doses between $1 \times 10^{13}$ and 2 $\times 10^{15} \mathrm{~cm}^{-2}$ at temperatures of $80 \mathrm{~K}$, nominal room temperature (RT), and $300{ }^{\circ} \mathrm{C}$. A markedly higher electrical activation was obtained in the samples implanted at $80 \mathrm{~K}$ compared to those implanted at RT or $300{ }^{\circ} \mathrm{C}$, attaining a maximum hole concentration of $2 \times 10^{19} \mathrm{~cm}^{-3}$. The redistribution of the $\mathrm{C}$ profile during rapid thermal annealing at temperatures from 700 to $950{ }^{\circ} \mathrm{C}$ for $10 \mathrm{~s}$ was found negligible, independently of the implantation temperature. Similar improvements in the electrical properties were also verified in samples implanted at $80 \mathrm{~K}$ with a lower energy of 60 $\mathrm{keV}$. We consider that despite the light mass of $\mathrm{C}$ ions, the reduced dynamic annealing at $80 \mathrm{~K}$ allows the accumulation of an abundance of As vacancies, which assist the $\mathrm{C}$ activation as a $p$-type dopant. () 2001 American Institute of Physics. [DOI: 10.1063/1.1356729]

$\mathrm{Be}, \mathrm{Mg}, \mathrm{Zn}$, and $\mathrm{Cd}$ ions are commonly implanted into GaAs to produce $p$-type doped layers. These column-II elements can be highly activated, yielding a hole concentration that reaches the $10^{19} \mathrm{~cm}^{-3}$ range. ${ }^{1}$ However, besides the advantages associated with the high electrical activation, the large diffusivity of column-II atoms at concentrations $>10^{18} \mathrm{~cm}^{-3}$ in GaAs (Ref. 2) constitutes a severe drawback when a shallow or abrupt profile is required. Therefore, the as-implanted profile redistributes significantly by indiffusion and outdiffusion, even during rapid thermal annealing (RTA). In particular, the up-hill diffusion of column-II elements in $\mathrm{GaAs},{ }^{3,4}$ i.e., the movement of the implanted atoms in the direction of the concentration gradient during the initial stage of annealing, introduces additional contribution to the profile redistribution.

Carbon is an amphoteric dopant in GaAs, which is preferentially incorporated in the As sublattice where it acts as a single-electron acceptor. In contrast with the column-II elements, $\mathrm{C}$ has a quite low diffusion coefficient, of less than $1 \times 10^{-16} \mathrm{~cm}^{2} / \mathrm{s}$ at $950{ }^{\circ} \mathrm{C}^{5}$ An extremely high hole concentration can be established (up to $5.8 \times 10^{20} \mathrm{~cm}^{-3}$ ) when $\mathrm{C}$ is introduced into GaAs during metalorganic molecular-beam epitaxial growth. ${ }^{6}$ In contrast, the electrical activation of $\mathrm{C}$ implanted in $\mathrm{GaAs}$ is considerably low, ${ }^{7}$ with the hole concentration typically lower than $1 \times 10^{18} \mathrm{~cm}^{-3}$. Co implantation of $\mathrm{C}$ with inert gas ions or with column-II or -III element ions has been employed to enhance the activation. ${ }^{8-12}$ The damage introduced by the coimplanted ions and/or the creation of As vacancies as a consequence of the incorporation of column-II or -III atoms in the Ga sublattice are claimed to be the causes which lead to activation enhancement. Among the applications of $\mathrm{C}$ doping in GaAs are the

${ }^{a)}$ Electronic mail: pudenzi@ifi.unicamp.br high-concentration doping of a transistor base in epitaxial of heterobipolar structures ${ }^{13}$ and the formation of buried $p$-type layers in field-effect transistors. ${ }^{14}$

Previous studies ${ }^{10-12}$ have demonstrated that the asimplanted damage is beneficial for $p$-type activation of C. It is well known that implantation damage is, to a large extent, determined by the intensity of the dynamic annealing. Therefore, one expects that during implantation of $\mathrm{C}$ ions at a very low temperature (like at $80 \mathrm{~K}$ ), in spite of the light ion mass, the necessary damage concentration to favor the activation of $\mathrm{C}$ would be accumulated. The correctness of this statement is demonstrated in the present investigation.

The samples used in this work are from semi-insulating liquid-encapsulated Czochralski-grown GaAs wafers of (100) orientation. C-ion implantation was performed at the energy of $1 \mathrm{MeV}$ using the "Tandetron" ion accelerator of the Physics Institute at Porto Alegre. The implantation was performed with the substrate at temperatures of $80 \mathrm{~K}$, nominal room temperature $(\mathrm{RT})$, or $300^{\circ} \mathrm{C}$, with doses ranging from $1 \times 10^{13}$ to $2 \times 10^{15} \mathrm{~cm}^{-2}$. In order to minimize channeling effects, the samples were tilted $10^{\circ}$ and rotated $25^{\circ}$ with respect to the $\langle 110\rangle$ direction. The as-implanted samples were submitted to capless RTA (Si proximity) for $10 \mathrm{~s}$ in $\mathrm{Ar}$ atmosphere in the temperature range from 700 to $950{ }^{\circ} \mathrm{C}$.

Hall-effect measurements in Van der Pauw devices ${ }^{15}$ provided the sheet resistance $\left(R_{s}\right)$, sheet carrier density $\left(p_{s}\right)$, and effective carrier mobility $\left(\mu_{\text {eff }}\right)$ values. The Ohmic contacts in the devices were prepared by manually applying In to the GaAs surface and then sintering at $\approx 300{ }^{\circ} \mathrm{C}$ during 3 min. The depth distribution of the $\mathrm{C}$ atoms was obtained by secondary ion mass spectrometry (SIMS) measurements with a $10 \mathrm{keV} \mathrm{Cs}{ }^{+}$beam at $45^{\circ}$ incidence on an MIQ-256 quadrupole microprobe. The crater depth was measured using a Dektak-3ST. Electrochemical $C-V(\mathrm{EC}-V)$ profiling was 


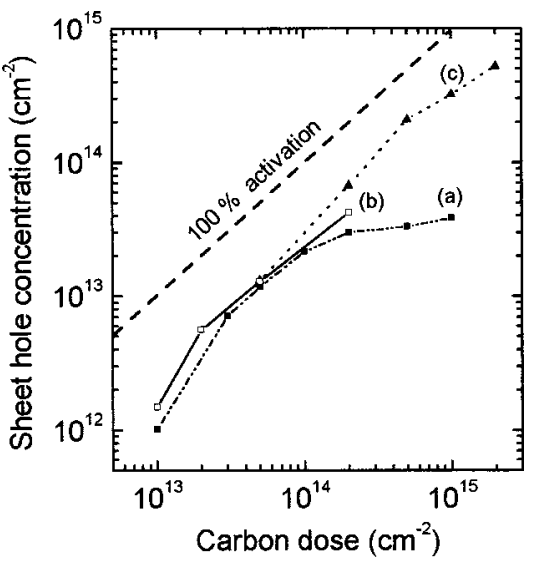

FIG. 1. Sheet hole concentration after annealing at $850^{\circ} \mathrm{C}$ for $10 \mathrm{~s}$ as a function of implanted $\mathrm{C}$-ion dose. The implantation temperatures were (a) nominal room temperature, (b) $300{ }^{\circ} \mathrm{C}$ and (c) $80 \mathrm{~K}$.

performed on annealed samples using equipment described elsewhere. ${ }^{16}$

The lowest annealing temperature that provided measurable electrical activation was $700{ }^{\circ} \mathrm{C}$ and the doped layers were always of $p$-type conductivity. In the RT-implanted samples, $p_{s}$ increased with the RTA temperature reaching a maximum at $850^{\circ} \mathrm{C}$ and then decreased slightly for higher temperatures.

Figure 1 shows the $p_{s}$ values versus the $\mathrm{C}$ dose after RTA conducted at $850^{\circ} \mathrm{C}$. Curves (a), (b), and (c) correspond to implantation at $\mathrm{RT}, 300^{\circ} \mathrm{C}$, and $80 \mathrm{~K}$, respectively. In the RT-implanted samples the electrical activation yield (EAY), i.e., the ratio of $p_{s}$ and the implanted dose, is practically constant $(\cong 20 \%)$ for doses $<1 \times 10^{14} \mathrm{~cm}^{-2}$ [see curve (a)]. However, for doses $>1 \times 10^{14} \mathrm{~cm}^{-2}, p_{s}$ saturates at $\approx 3$ $\times 10^{13} \mathrm{~cm}^{-2}$. This means that the EAY decreases essentially for doses $>1 \times 10^{14} \mathrm{~cm}^{-2}$. Since $\mathrm{C}$ is an amphoteric dopant in GaAs, ${ }^{17}$ one could suppose that such decrease in the $p$-type doping efficiency results from donor compensation, i.e., from $\mathrm{C}$ incorporated in the Ga sublattice. However, this hypothesis cannot be supported by the mobility data from the present work. For example, in samples implanted at RT with the doses of $2 \times 10^{14} \mathrm{~cm}^{-2}$ (sample A) and $1 \times 10^{15} \mathrm{~cm}^{-2}$ (sample B), the measured $p_{s}$ and $\mu_{\text {eff }}$ values after RTA at $900{ }^{\circ} \mathrm{C}$ are, respectively, $2.8 \times 10^{13} \mathrm{~cm}^{-2}$ and $208 \mathrm{~cm}^{2} / \mathrm{V} \mathrm{s}$ (sample A) and $3.3 \times 10^{13} \mathrm{~cm}^{-2}$ and $185 \mathrm{~cm}^{2} / \mathrm{V} \mathrm{s}$ (sample B). One should note that the respective values of $p_{s}$ and $\mu_{\text {eff }}$ in samples A and B are not too different. Considering the amphoteric activation of $\mathrm{C},{ }^{17}$ the concentration of ionized scattering centers $\left(N_{i}\right)$ in sample $\mathrm{B}$ should be $\cong 5$ times higher than in sample A. Assuming scattering of holes by phonons and ionized centers ${ }^{18}$ the calculated hole mobility results in $71 \mathrm{~cm}^{2} / \mathrm{V} \mathrm{s}$ for sample B, which is well below the experimental value $\left(185 \mathrm{~cm}^{2} / \mathrm{V} \mathrm{s}\right)$. However, a mobility of 192 $\mathrm{cm}^{2} / \mathrm{V}$ s is estimated assuming scattering by $N_{i}=P_{s}$, in close agreement with the experimental value. Based on this reasoning, one can infer that the substantial concentration of $\mathrm{C}$ atoms nonactivated during RTA in samples implanted at RT to high doses remains electrically neutral. Very likely, the neutral $\mathrm{C}$ atoms form precipitates in the GaAs matrix like those observed by electron microscopy analysis. ${ }^{19}$

Curve (b) in Fig. 1 shows the dose dependence of the $\mathrm{C}$ electrical activation in samples implanted at $300^{\circ} \mathrm{C}$ after

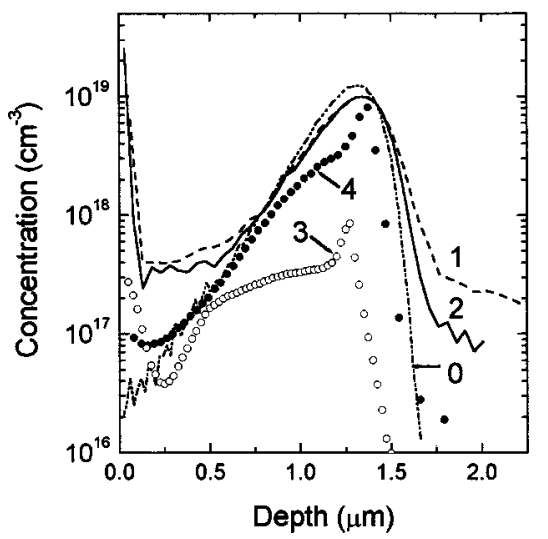

FIG. 2. Curve $(0)$ is the C-atom distribution estimated by the TRIM code simulation. Curves (1) and (2) are profiles of $\mathrm{C}$ atoms measured by SIMS after annealing at $950{ }^{\circ} \mathrm{C}$ for $10 \mathrm{~s}$ in samples implanted with a dose of 5 $\times 10^{14} \mathrm{~cm}^{-2}$ at nominal room temperature (sample I) and at $80 \mathrm{~K}$ (sample II), respectively. Curves (3) and (4) are acceptor profiles measured by the electrochemical $C-V$ method in samples I and II, respectively.

RTA at $850{ }^{\circ} \mathrm{C}$. There is only a marginal improvement in the electrical activation in the hot-implanted samples compared to those implanted at RT. This result clearly indicates that the implantation of $\mathrm{C}$ ions at high temperature is not effective in increasing the activation efficiency.

The dependence of electrical activation on the dose implanted at $80 \mathrm{~K}$ is depicted in curve (c) of Fig. 1. The data in curve (c) show remarkable electrical activation for doses $>5 \times 10^{13} \mathrm{~cm}^{-2}$. One notices that $p_{s}$ increases with the dose, with no propensity for saturation. The EAY reached a maximum value of $42 \%$ (for the dose of $5 \times 10^{14} \mathrm{~cm}^{-2}$ ), which is 1.8 times higher than the corresponding value in the RTimplanted samples (22\% for doses of $3-5 \times 10^{13} \mathrm{~cm}^{-2}$ ).

Curves (1) and (2) in Fig. 2 are the SIMS concentration depth profiles of $\mathrm{C}$ after RTA at $950{ }^{\circ} \mathrm{C}$ in samples implanted to a dose of $5 \times 10^{14} \mathrm{~cm}^{-2}$ at RT (sample I) and $80 \mathrm{~K}$ (sample II), respectively. The concentration depth profile estimated by TRIM (Ref. 20) code simulation is included in curve (0), for comparison. The SIMS profiles from sample I before annealing (not shown) and after annealing [curve (1)] closely superimpose, clearly confirming the low diffusivity of C. A near coincidence between the SIMS profiles and the TRIMsimulated one occurs for depths from 0.7 to $1.4 \mu \mathrm{m}$. The tail in the measured profiles for depths $>1.4 \mu \mathrm{m}$ probably results from imperfect channeling suppression. In the coldimplanted sample the tail is less pronounced, very likely because the higher accumulated implantation damage contributes to dechanneling. Close to the surface, from depths of $0.1-0.7 \mu \mathrm{m}$, the measured $\mathrm{C}$ concentrations are $2-3$ times higher than the TRIM-predicted ones. The causes for this discrepancy are unclear at present.

The EC-V depth profile for the acceptors obtained after RTA at $950{ }^{\circ} \mathrm{C}$ is shown in Fig. 2 in curves (3) and (4) for samples I and II, respectively. One can observe that the acceptor concentrations in sample I are well below those of C atoms along the entire profile [compare curves (3) and (1) in Fig. 2]. This result correlates with the low values of $p_{s}$ $(\approx 7 \%$ of implanted dose) measured in sample I. On the other hand, the acceptor profile in sample II reproduces approximateiy the $\mathrm{C}$ atom profile [compare curves (4) and (2) in Fig. 


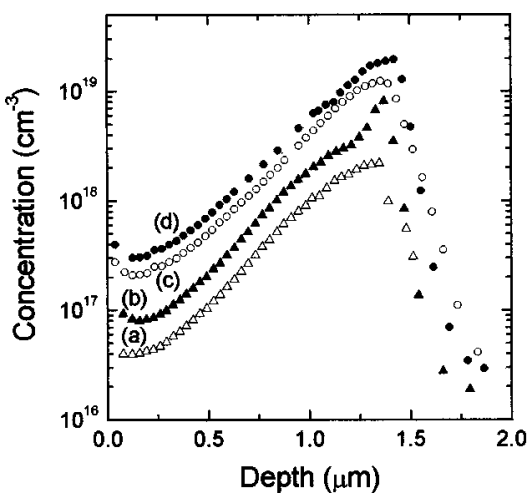

FIG. 3. Profiles of acceptors obtained by the electrochemical $C-V$ method in samples implanted with $\mathrm{C}$ ions at $80 \mathrm{~K}$ and annealed at $850{ }^{\circ} \mathrm{C}$ for $10 \mathrm{~s}$ to doses of (a) $2 \times 10^{14} \mathrm{~cm}^{-2}$, (b) $5 \times 10^{14} \mathrm{~cm}^{-2}$, (c) $1 \times 10^{15} \mathrm{~cm}^{-2}$, and (d) 2 $\times 10^{15} \mathrm{~cm}^{-2}$.

2], indicating that a substantial fraction of the implanted dose was activated.

Figure 3 shows, in curves (a)-(d), the EC-V acceptor profiles after RTA at $850{ }^{\circ} \mathrm{C}$ measured in samples implanted at $80 \mathrm{~K}$ with doses in the range from $2 \times 10^{14}$ to 2 $\times 10^{15} \mathrm{~cm}^{-2}$. It is interesting to notice that the shape of profiles (a)-(d) closely resembles the TRIM distribution [curve (0) in Fig. 2]. In addition, the concentration of acceptors increases approximately proportional to the implantation dose. For the implanted dose of $2 \times 10^{15} \mathrm{~cm}^{-2}$, the acceptor concentration at the peak reached $2 \times 10^{19} \mathrm{~cm}^{-3}$, which is about 20 times higher than the maximum value normally obtained in GaAs implanted with C at RT. The corresponding $R_{s}$ and $\mu_{\text {eff }}$ values are $150 \Omega / \square$ and $80 \mathrm{~cm}^{2} / \mathrm{V} \mathrm{s}$, respectively. This activated concentration is comparable to the highest obtained by $\mathrm{Ga}^{+}+\mathrm{C}^{+}$coimplantation. ${ }^{9}$

The $\mu_{\text {eff }}$ in the samples implanted at $80 \mathrm{~K}$ decrease with the increase of $p_{s}$, according to the common concentration dependence model, ${ }^{18}$ meaning that the same scattering mechanisms take place in samples implanted at $80 \mathrm{~K}$ and RT.

The improved activation of $\mathrm{C}$ in samples implanted at 80 $\mathrm{K}$ should be attributed to the higher as-implanted damage concentration. During the initial stage of RTA, an oversaturation in the point-defect concentrations should be established, by virtue of the damage dissolution. The presence of a high concentration of As vacancies should facilitate the incorporation of $\mathrm{C}$ atoms in the As sublattice, leading to the enhancement of the EAY of C. In contrast, during the C implantation at $\mathrm{RT}$ or $300^{\circ} \mathrm{C}$, intense recombination of point defects takes place in the collision cascades. During annealing, a lower concentration of As vacancies is present and, hence, a lower EAY of $\mathrm{C}$ results.

In a separate experiment, $\mathrm{C}$ ions were implanted to the dose of $5 \times 10^{14} \mathrm{~cm}^{-2}$ and energy of $60 \mathrm{keV}$ at RT and at 80 $\mathrm{K}$. The EAY values measured after RTA at $850^{\circ} \mathrm{C}$ for $10 \mathrm{~s}$ are $19 \%$ and $0.4 \%$, for the $80 \mathrm{~K}$ and RT-implanted samples, respectively. These results demonstrate that the implantation at $80 \mathrm{~K}$ is also highly effective in improving the activation of $\mathrm{C}$ implanted at a low energy.

In summary, the influence of the substrate temperature during C-ion implantation on the electrical activation was investigated. A significantly higher electrical activation yield was obtained in samples implanted at $80 \mathrm{~K}$ compared to those implanted at RT or $300{ }^{\circ} \mathrm{C}$. The acceptor concentration in the $80 \mathrm{~K}$ implanted samples reached a value of 2 $\times 10^{19} \mathrm{~cm}^{-3}$ at the profile peak, which is $\approx 20$ times higher than in the best activated RT-implanted samples. From the dependence of the effective hole mobility on the sheet hole concentration, it was inferred that $\mathrm{C}$ atoms nonactivated as acceptors remain electrically neutral. We have demonstrated that $p$-type layers in GaAs of low sheet resistance and negligible profile redistribution during rapid thermal annealing can be formed via low-temperature $(80 \mathrm{~K}) \mathrm{C}$-ion implantation.

This work was partially supported by Conselho Nacional de Pesquisas (CNPq), Fundação de Amparo à Pesquisa do Estado do Rio Grande do Sul (FAPERGS), and Fundação de Amparo à Pesquisa do Estado de São Paulo (FAPESP).

${ }^{1}$ J. P. de Souza and D. K. Sadana, in Handbook on Semiconductors, edited by S. Mahajan (North Holland, Amsterdan, 1994), Vol. 3b, p. 2036.

${ }^{2}$ Y. M. Haddara, C. C. Lee, J. C. Hu, M. D. Deal, and J. C. Bravman, Mater. Res. Bull. 20, 41 (1995).

${ }^{3}$ H. Robinson, M. D. Deal, and D. A. Stevenson, Appl. Phys. Lett. 56, 554 (1990).

${ }^{4}$ H. G. Robinson, M. D. Deal, G. Amaratunga, P. B. Griffin, D. A. Stevenson, and J. D. Plummer, J. Appl. Phys. 71, 2615 (1992).

${ }^{5}$ C. R. Albernathy, S. J. Pearton, F. Ren, W. S. Hobson, T. R. Fullowan, A. S. Katz, A. S. Jordan, and J. Kovalchik, J. Cryst. Growth 105, 375 (1990).

${ }^{6}$ K. Saito, E. Tokumitsu, T. Akatsuka, M. Miyauchi, T. Yamada, M. Konagai, and K. Takahashi, J. Appl. Phys. 64, 3975 (1988).

${ }^{7}$ Y. Danilov, V. T. Karmanov, P. V. Pavlov, and E. A. Pitirimova, Sov. Phys. Semicond. 15, 971 (1993).

${ }^{8}$ B. K. Shin, J. E. Ehret, Y. S. Park, and M. Stefiniw, J. Appl. Phys. 49, 2988 (1978)

${ }^{9}$ S. J. Pearton and C. R. Albernathy, Appl. Phys. Lett. 55, 678 (1989).

${ }^{10}$ A. J. Moll, K. M. Yu, W. Walukiewics, W. L. Hansen, and E. E. Haller, Appl. Phys. Lett. 60, 2383 (1992).

${ }^{11}$ R. Morton, B. Shu, S. S. Lau, and D. B. Poker, Appl. Phys. Lett. 66, 1132 (1995).

${ }^{12}$ R. Morton, S. S. Lau, D. B. Poker, P. K. Chu, F. F. Fung, and N. Wang, J. Appl. Phys. 84, 4929 (1998).

${ }^{13}$ J. Shirakashi, T. Azuma, F. Fukuchi, M. Konagai, and K. Takahashi, J. Cryst. Growth 150, 585 (1995).

${ }^{14}$ J. C. Zolper, M. E. Sherwin, A. G. Baca, R. J. Shul, J. F. Klem, and V. M. Hietala, IEEE Electron Device Lett. 15, 493 (1994).

${ }^{15}$ L. J. Van der Pauw, Philips Res. Rep. 13, 1 (1958).

${ }^{16}$ I. V. Irin and A. V. Murel, Instrum. Exp. Tech. 36, 918 (1993).

${ }^{17}$ W. H. van Berlo, J. Appl. Phys. 73, 2765 (1993).

${ }^{18}$ S. Blakemore, J. Appl. Phys. 53, R123 (1982).

${ }^{19}$ D. I. Piskunov, Y. A. Danilov, S. K. Maksimov, and E. A. Pitirimova, Phys. Status Solidi A 96, 141 (1986).

${ }^{20}$ J. F. Ziegler, J. P. Biersack, and U. Littmark, in The Stopping and Range of Ions in Solids (Pergamon, New York, 1985). 